\title{
Real-time recording of annuloplasty suture dehiscence reveals a potential mechanism for dehiscence cascade
}

\author{
Eric L. Pierce, BS, ${ }^{\mathrm{a}}$ Javier Gentile, MD, ${ }^{\mathrm{b}}$ Andrew W. Siefert, PhD, ${ }^{\mathrm{c}}$ Robert C. Gorman, MD, ${ }^{\mathrm{b}}$ \\ Joseph H. Gorman III, MD, ${ }^{b}$ and Ajit P. Yoganathan, PhD, ${ }^{a}$ Atlanta and Alpharetta, Ga, and Philadelphia, Pa
}

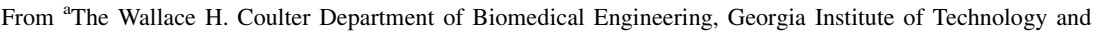
Emory University, Atlanta, Ga; ${ }^{\mathrm{b}}$ Gorman Cardiovascular Research Group, Perelman School of Medicine, University of Pennsylvania, Philadelphia, Pa; and ${ }^{\mathrm{C}}$ InSciTech, Inc, Alpharetta, Ga.

This study was supported by the National Science Foundation (Fellowship DGE-1148903, to E.L.P.) and the National Heart, Lung, and Blood Institute (Grant HL113216).

Disclosures: Authors have nothing to disclose with regard to commercial support.

Received for publication Nov 8, 2015; revisions received Jan 7, 2016; accepted for publication Jan 23, 2016; available ahead of print March 11, 2016.

Address for reprints: Ajit P. Yoganathan, PhD, 387 Technology Circle NW, Suite 200, Atlanta, GA 30313 (E-mail: ajit.yoganathan@bme.gatech.edu).

J Thorac Cardiovasc Surg 2016;152:e15-7

$0022-5223 / \$ 36.00$

Copyright (c) 2016 by The American Association for Thoracic Surgery

http://dx.doi.org/10.1016/j.jtcvs.2016.01.043
}

We present a case of annuloplasty suture dehiscence in a live ovine model, with novel, real-time suture force recordings throughout the event.

\section{CLINICAL SUMMARY}

Following repair of mitral regurgitation, annuloplasty ring suture dehiscence is a major cause of postoperative failure, accounting for approximately $19 \%$ of reoperations. ${ }^{1}$ Dehiscence may occur at 1 or multiple suture positions. We recently reported novel transducers capable of quantifying tension in individual sutures in the beating heart after mitral annuloplasty. ${ }^{2}$ We have expanded these methods to evaluate the effects of ring size, shape, and ventricular function on suture forces, to identify physiological and device-specific factors that may affect suture dehiscence risk. As part of this study, a Profile3D ring (size, 26; Medtronic, Dublin, Ireland), instrumented with transducers, was implanted in a healthy 45-kg subject (annulus size, 30). Implantation was analogous to clinical annuloplasty, using 10 2-0 $\mathrm{Ti} \cdot$ Cron sutures (Covidien, Dublin, Ireland) with suture bite approximately $10 \mathrm{~mm}$ wide and $1.5 \mathrm{~mm}$ deep (Figure 1). The transducers did not affect ring or suture function. ${ }^{2}$ Animal care was provided in compliance with protocols approved by the Institutional Animal Care and Use Committee at University of Pennsylvania, in accordance with National Institutes of Health guidelines for humane care.

The animal was weaned from cardiopulmonary bypass, and resting hemodynamics were reestablished. To investigate the impact of hypercontractility on annuloplasty suture tension, a $0.2-\mu \mathrm{g}$ intravenous bolus of epinephrine was administered, causing a rise in LVP to $195 \mathrm{~mm} \mathrm{Hg}$ over 30 to 40 seconds. Suture force within a cycle trended positively with LVP at every position (Figure 2). One suture, located between the trigones along the anterior aspect, experienced twice the peak loading of any other

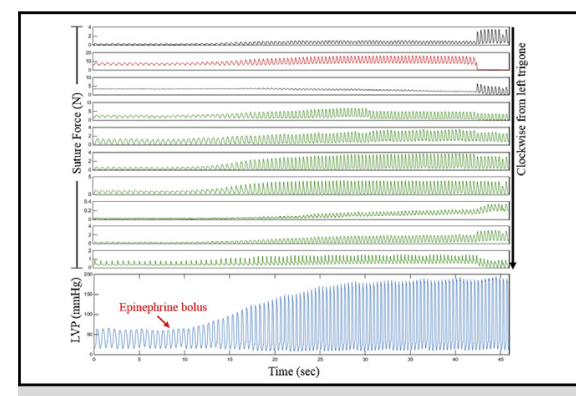

Dehiscence of an annuloplasty suture adds significant tension to its adjacent 2 sutures.

Central Message

Dehiscence of a mitral annuloplasty ring suture redistributes tension to 2 adjacent sutures, creating a risk for further dehiscence.

See Editorial Commentary page e19.

suture at all LVPs. At an LVP of $188 \mathrm{~mm} \mathrm{Hg}$, a dramatic decrease in force was observed at this position, from $16.7 \mathrm{~N}$ to $0.6 \mathrm{~N}$. Simultaneously, peak forces increased at the 2 adjacent sutures, one by $3.1 \mathrm{~N}$ and the other by $2.6 \mathrm{~N}$. Two other sutures experienced small increases $(1.3 \mathrm{~N}$ and $0.3 \mathrm{~N}$ ); but force decreased at all other sutures. After the animal was euthanized, visual examination revealed that the suture in question had torn through the annulus tissue, likely owing to technical misplacement above the annular hinge (Figure 1,D). The suture itself remained intact. The ruptured tissue was not examined histologically.

\section{DISCUSSION}

This case provides the first quantification of a tensile force responsible for annuloplasty ring suture dehiscence in the beating heart. After a $16.7 \mathrm{~N}$ load induced dehiscence, a combined $5.7 \mathrm{~N}$ shifted to the 2 adjacent sutures. This observation provides a likely mechanism whereby a single problematic suture could induce a cascade of dehiscence at multiple anchor points, as observed clinically. ${ }^{3}$ A less eccentric redistribution of force across the remaining sutures may be preferable.

Greater suture loads may be expected along the anterior annulus in general. Cyclic changes in the anterior annulus's saddle shape ${ }^{4}$ due to aortic filling and fibrous trigone motion, as well as its denser collagen, ${ }^{5}$ may augment overall suture tension in this region. Nonetheless, it is noteworthy that the observed force distribution was so highly concentrated 


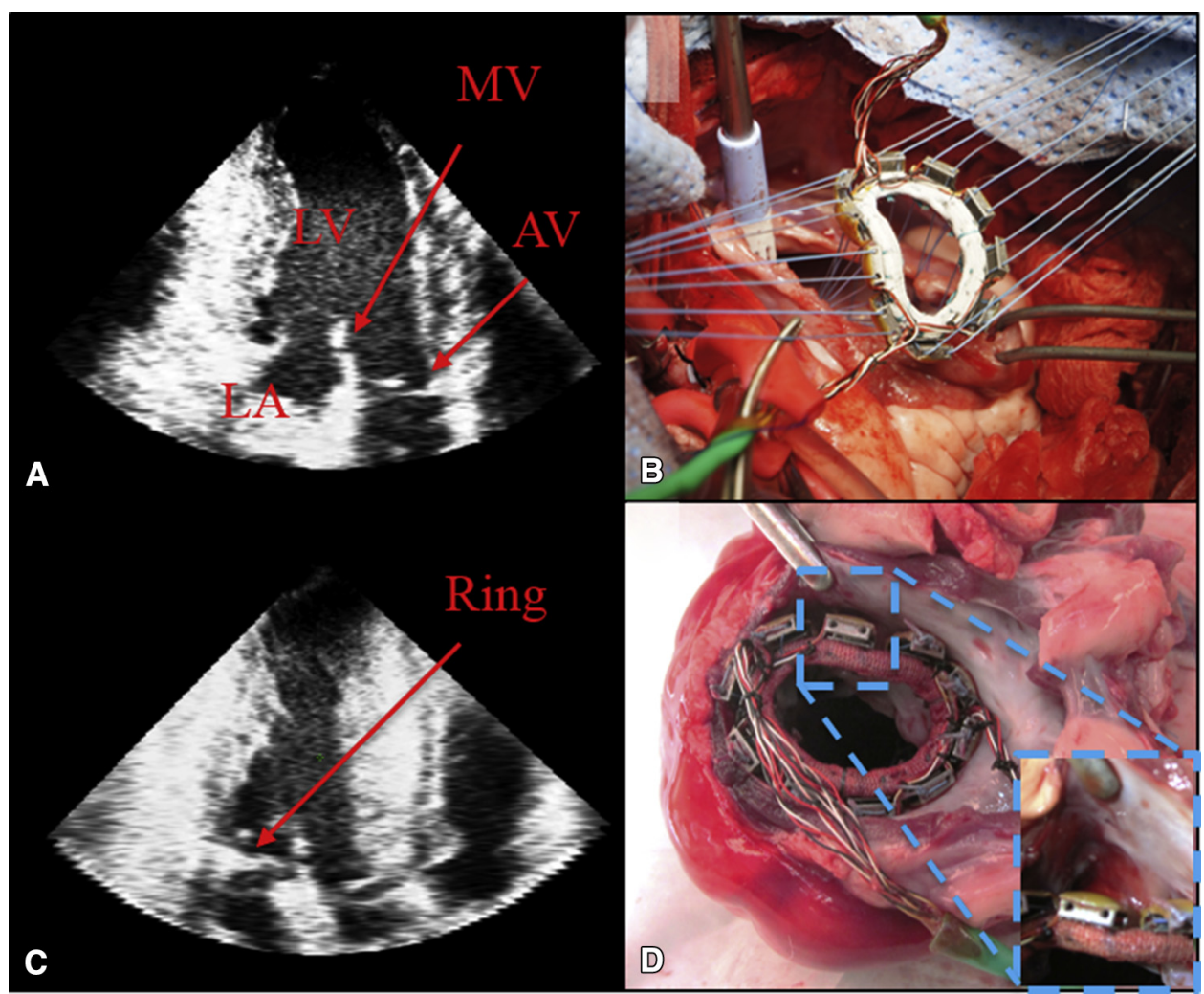

FIGURE 1. A and B, An annuloplasty ring, instrumented to record tensile forces on individual sutures, was implanted in the mitral valve of a healthy ovine subject using standard technique. C, Implantation was unremarkable. D, Following LVP elevation above $188 \mathrm{~mm} \mathrm{Hg}, 1$ suture dehisced. $L A$, Left atrium; $L V$, left ventricle; $M V$, mitral valve; $A V$, aortic valve.

on the single failed suture, even at lower LVPs. This case was likely a consequence of misplacement of the suture in question; we believe that placement too high above the annular hinge heightened suture tension by adding an out-of-plane force component at that position. Beyond suture placement, valve-specific anatomy and/or ring selection also may contribute to the risk of dehiscence. Degenerative or ischemic disease may further complicate loading dynamics and suture pullout thresholds. Ultimately, any steps during device selection, suture placement, and tie-down that minimize sharp force concentrations on single sutures will likely help ensure prosthesis security. To concretely identify such steps, an improved understanding of the factors that most directly relate to suture dehiscence risk is first necessary. These factors are the subjects of ongoing work.
We thank Charles Bloodworth and Ikechukwu Okafor for data analysis and critical review.

\section{References}

1. Gillinov AM, Cosgrove DM, Lytle BW, Taylor PC, Stewart RW, McCarthy PM, et al. Reoperation for failure of mitral valve repair. J Thorac Cardiovasc Surg. 1997; 113:467-75.

2. Siefert AW, Pierce EL, Lee M, Jensen M $\varnothing$, Aoki C, Takebayashi S, et al. Suture forces in undersized mitral annuloplasty: novel device and measurements. Ann Thorac Surg. 2014;98:305-9.

3. Ciobanu AO, Griffin SC, Bennett S, Vinereanu D. Catastrophic mitral prosthesis dehiscence diagnosed by three-dimensional transesophageal echocardiography. J Clin Ultrasound. 2014;42:249-51.

4. Rausch MK, Bothe W, Kvitting J-PE, Swanson JC, Ingels NB Jr, Miller DC, et al. Characterization of mitral valve annular dynamics in the beating heart. Ann Biomed Eng. 2011;39:1690-702.

5. Gunning GM, Murphy BP. Determination of the tensile mechanical properties of the segmented mitral valve annulus. J Biomech. 2014;47:334-40. 


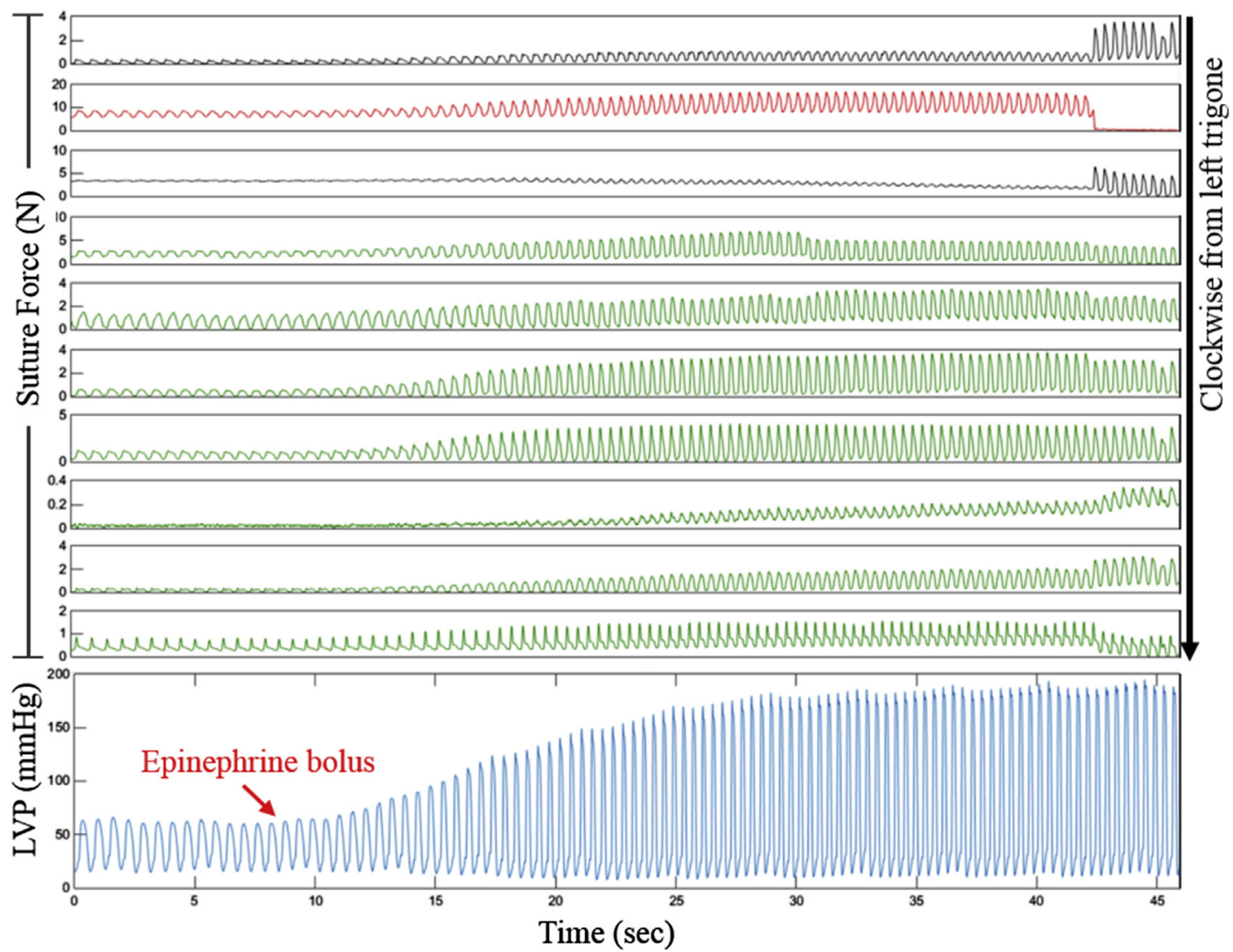

FIGURE 2. The failed suture dehisced following a peak force of $16.7 \mathrm{~N}($ red $) ; 5.7 \mathrm{~N}$ of this force shifted to the 2 adjacent sutures (black). Loading on all other sutures either increased slightly $(<1.3 \mathrm{~N})$ or decreased (green). LVP, Left ventricular pressure. 